\title{
Seasonal variability in the diet of juvenile European catfish, Silurus glanis, in the Arno River (Italy) in Florence
}

\author{
Phillip J. Haubrock
}

Received - 03 November 2020/Accepted - 11 March 2021. Published online: 31 March 2021; OInland Fisheries Institute in Olsztyn, Poland Citation: Haubrock, P.J. (2021). Seasonal variability in the diet of juvenile European catfish, Silurus glanis, in the Arno River (Italy) in Florence. Fisheries \& Aquatic Life 29(1), 54-61

\begin{abstract}
While approaches for assessing the impact of invasive species are advancing, fundamental autoecological information such as feeding preferences is often unavailable for many invasive species. The European catfish, Silurus glanis, is a well-known, high-impact invasive predator; however, there remain considerable gaps in knowledge about its feeding preferences and biotic interactions that limit ecological impact predictions for this predator. This study is an investigation of seasonal variability in this predator's diet during the juvenile life stage using the Arno River, Italy as a model system. This study identified significant differences across seasons, provided further information on the dietary spectrum of this species, and raised important questions for further study.
\end{abstract}

Keywords: dietary analysis, stomach contents, invasive species

\section{Introduction}

As a growing element of anthropogenically-driven global change, biological invasions significantly disrupt ecosystems (Malcolm and Markham 2000, Bellard et al. 2016, Crystal-Ornelas and Lockwood 2020) and show no signs of subsiding (Seebens et al. 2017). The ecological impacts of biological invasions can potentially challenge conservation efforts and management interventions (Hulme et al. 2009, Cuthbert et al. 2021). Freshwater ecosystems are particularly susceptible to increased introductions and the spread of non-native species (Poulin et al. 2011) and are prone to be modified by them (Gallardo et al. 2016, Haubrock et al. 2021a). Indeed, the already complex ecological interactions among species are further complicated by interactions with novel invasive species in communities (Stellati et al. 2019), but interactions among invasive species themselves also pose problems (Haubrock et al. 2019).

In many Europeans countries, the presence of Phillip J. Haubrock [ $\left[\Xi^{\prime}\right]$
Senckenberg Research Institute and natural History Museum Frankfurt, Department of River Ecology and Conservation, 63571 Gelnhausen, Germany

University of South Bohemia in České Budějovice, Faculty of Fisheries and Protection of Waters, South Bohemian Research Center of Aquaculture and Biodiversity of Hydrocenoses, Zátiší 728/II, 38925 Vodňany, Czech Republic

E-mail: Phillip.Haubrock@Senckenberg.de non-native fishes has increased over the past 25 years (Gherardi et al. 2008, Nocita et al. 2017). Despite some unintentional introductions, most species have been introduced intentionally for angling and other purposes (Nunes et al., 2015), despite indications of noteworthy economics burdens (Haubrock et al. 2021b). In Europe, one particular example is

\footnotetext{
(c) Copyright by Stanisław Sakowicz Inland Fisheries Institute in Olsztyn.

C 2021 Author(s). This is an open access article licensed under the Creative Commons Attribution-NonCommercial-NoDerivs License (http://creativecommons.org/licenses/by-nc-nd/3.0/).
} 
Italy, where freshwater ecosystems have suffered from the introduction of various aquatic invasive species in the past (Nocita et al. 2017), resulting in the establishment of more than 150 aquatic species (at least 64 invertebrates and 48 vertebrates) contributing to at least $2 \%$ of the inland-water fauna (Gherardi et al. 2008). One such species is the European catfish, Silurus glanis L., a native of northeastern Europe and Asia. S. glanis is known to be the largest freshwater Osteichthyes in Europe (maximum size $2.7 \mathrm{~m}$ and $130 \mathrm{~kg}$; Boulętreau et al. 2016). In the last two decades, mostly facilitated by angling activities, drastic increases in its population size and distribution have been observed (Copp et al. 2009, Alexander et al. 2014, Cunico and Vitule 2014).

S. glanis was introduced in Italy in the 1990 s (Balma et al. 1989), and its spread was facilitated intentionally throughout the Italian peninsula with diverse impacts on native and newly-introduced species (Castaldelli et al. 2013). In the Florentine stretch of the Arno River, S. glanis has been reported by anglers since 2004 (Gualtieri and Mecatti 2005). Within a few years, this species became a popular target of anglers, which was concomitant with considerable positive economic effects (Rees et al. 2017, Cucherousset et al. 2018) but negative environmental impacts (Copp et al. 2009, Castaldelli et al. 2013). Since 2016, a decrease in the abundance of large individuals and a greater relative frequency of juveniles without prey in their guts has been observed in the Arno River. These observations have been linked to (a) competition with another invader, the North American channel catfish, Ictalurus punctatus (Raf.), (b) control efforts, and (c) angling pressure (Haubrock et al. 2019, 2020). However, the data on the diet of $S$. glanis presented in these study were constrained to one season and contributed only preliminary or anecdotal information on this invader's $\operatorname{diet}$ (Gualtieri and Mecatti 2005). Accordingly, there remains little information on which taxa are impacted by this species through predation.

To tackle this obvious gap, we assembled dietary information from the $S$. glanis juvenile life stage in the Arno River. We hypothesized that a more detailed analysis of this invasive fish's diet could indicate potential reasons for its decline while simultaneously revealing missing information on its diet.

\section{Method}

\section{Study site, sampling, and sample preparation}

A detailed description on the flow regime of the Arno River and its species community was summarized previously (Nocita, 2002, Nocita and Zerunian 2007, Haubrock et al. 2019). Sampling was conducted from late spring (April to the beginning of June) and fall (August to September) 2018 in the section of the Arno River that flows through the city of Florence (43.765606, 11.268234; DATUM WGS84). Information on the $S$. glanis diet sampled during spring was obtained from Haubrock et al. (2019). This data was supplemented with additional $S$. glanis specimens caught in fall. Both datasets were created using information from specimens caught with standard fishing rods and by local fishers using a variety of bait fishing techniques. Overall, 71 individuals (spring 39, Haubrock et al. 2019; fall - 32) were collected. The total length (TL; cm) of all specimens was measured to the nearest $1 \mathrm{~mm}$. Values reported in the text are averages +/- standard deviation. The specimens were stored in a freezer $\left(-20^{\circ} \mathrm{C}\right)$ until the stomach contents were extracted for dietary analyses.

\section{Dietary analyses}

The dietary analysis was based only on the cardiac, cecum, and pyloric parts of the digestive tract without discarding the contents of the intestine. Both algae and detritus were ranked according to their occurrence in relation to other prey: $0=$ no occurrence, 1 = low occurrence, 2 = equal occurrence, and 3 = dominating occurrence. Bait used for the sampling were excluded and not counted in the dietary analysis. Because of difficulties distinguishing between specimens of partially digested Alburnus alburnus (L.) and Pseudorasbora parva (Temmick \& 
Schlegel), these two species were classified as small $(<5 \mathrm{~cm})$ and large $(>5 \mathrm{~cm})$ cyprinids. For both seasons sampled, feeding intensity was calculated using the vacuity index $\left(\mathrm{V}_{\mathrm{I}}\right)$ individually as the percentage of empty stomachs in relation to stomachs that contained prey items (Batistic et al. 2005). Diet breadth was estimated with Levin's index formula (Whittaker et al. 1973): $B_{i}=\frac{1}{p \sum_{i}^{2}}$ where $B_{i}$ is the standardized index of diet breadth for specimen $i$ and $p$ the sum of the squared proportion of each prey item of specimen $i$ (Levin 1968). For further analyses, the stomach content data were expressed as frequency of occurrence $(\mathrm{F} \%=$ number of stomachs containing each food item in relation to the total number of full stomachs) and abundance ( $\mathrm{N} \%=$ the number of individuals of each food item in relation to the total number of individuals). With these, the prominence value (PV) for each dietary component was estimated according to Hickley et al. (1994): $P V=N \% \times \sqrt{F \%}$ to estimate diet-overlap index $\alpha$ using the formula by Schoener (1986): $\alpha=1-0.5\left(\sum_{i=1}^{n}\left|P V_{x i}-P V_{y i}\right|\right)$, where $n$ is the number of food items, $P V x_{i}$ the prominence value of food item i in species $x_{i}$, and $P V_{y i}$ is the prominence values of food item $i$ in species $y$. This index ranges between 0 , i.e., no overlap, and 1 , when diets are identical (Wallace 1981). Pianka's measure of diet based niche overlap (Pianka 1974) for specimens of $S$. glanis ( $j$, individuals caught in spring; $k$, individuals caught in fall) was calculated with the formula $0_{j k}=\frac{\sum_{j}^{n} p_{j} p_{k}}{\sqrt{\sum_{i}^{n} p_{j}^{2} \sum_{i}^{n} p_{k}^{2}}}$, where $p_{i j}$ and $p_{i k}$ are the proportions of the $i^{\text {th }}$ resource used by the $j^{\text {th }}$ and $k^{\text {th }}$ individuals from each season. Both estimates for diet overlap were used together, as Pianka's measure of niche overlap alone can be insufficient to identify a relation between niche overlap and competition, i.e., resource partitioning (Krebs 1998).

\section{Statistical analyses}

First, we tested if the total length of individuals caught in spring and fall differed significantly using the Student t-test (Zimmerman 1987). Second, using the stomach content records from each specimen sampled and both seasons, a permutational analysis of variance (PERMANOVA; two fixed factors - size and season; sums of squares: type II; 9999 permutations; partial permutation of residuals under a reduced model) was used to test if the diet, and, thus, feeding behavior, differed temporally and/or according to fish size. Additionally, we applied a canonical analysis of principal coordinates (CAP), which is a flexible, meaningful constrained ordination suitable for ecological abundance data. CAP was applied to prey abundances for the factors of size and season. Using the envfit function in R, we projected significantly correlated factors and prey items onto the relevant CAP axes. All statistical analyses were performed using the R "Vegan" package (Oksanen et al. 2007). The level of significance for all tests under which the null hypothesis was rejected was $\alpha=0.05$.

\section{Results}

The individuals collected differed in size, and those sampled in spring $(27.1 \pm 1.1 \mathrm{~cm})$ were significantly larger (t: 3.41, df: 53.73, p: <0.05) than those collected in fall (20.58 \pm 9.2$)$. A considerable number of stomachs was found empty from both sets of specimens (spring: 25/43, $\mathrm{V}_{\mathrm{I}}: 58 \%$; fall: 11/32, $\mathrm{V}_{\mathrm{I}}: 34 \%$ ). Overall, 18 items were identified in the stomachs, including biotic components from both aquatic and terrestrial environments and abiotic items (i.e., pebbles) (Table 1). The items that occurred resulted in a medium $\left(O_{i j}\right.$ : 0.365$)$ to high overlap $(\alpha: 0.737)$ between the two seasons, and they indicated a wider niche in spring (B: 7.3) than in fall (B: 5.6).

PERMANOVA identified the occurrence of prey as significantly different according to season (df:1; $\mathrm{R}^{2}$ : 0.04971; F: 3.8987; p: 0.0477) but not according to total size (df:1; $\mathrm{R}^{2}$ : 0.0266; F: 2.0850; p: 0.06316) 
Table 1

Results of dietary analysis of S. glanis in spring and fall; N\% = number of occurrence; F\% = frequency of occurrence; $\mathrm{PV}=$ prominence value; see Haubrock et al. (2019)

\begin{tabular}{|c|c|c|c|c|c|c|}
\hline \multirow[b]{2}{*}{ Prey } & \multicolumn{3}{|c|}{ Spring $(n=39)$} & \multicolumn{3}{|c|}{ Fall $(\mathrm{n}=32)$} \\
\hline & $\mathrm{N} \%$ & $\mathrm{~F} \%$ & PV & $\mathrm{N} \%$ & $\mathrm{~F} \%$ & PV \\
\hline Detritus $(0,1,2,3)$ & 13.79 & 9.30 & 0.04 & 7.79 & 15.63 & 0.03 \\
\hline Algae $(0,1,2,3)$ & 13.79 & 9.30 & 0.04 & 1.30 & 3.13 & 0.00 \\
\hline Snails (aquatic) & 0.00 & 0.00 & 0.00 & 1.30 & 3.13 & 0.00 \\
\hline Stones & 6.90 & 4.65 & 0.01 & 0.00 & 0.00 & 0.00 \\
\hline Plant seeds (terrestrial) & 3.45 & 2.33 & 0.01 & 0.00 & 0.00 & 0.00 \\
\hline Insect larvae & 3.45 & 2.33 & 0.01 & 32.47 & 18.75 & 0.14 \\
\hline Insect adult & 0.00 & 0.00 & 0.00 & 2.60 & 6.25 & 0.01 \\
\hline Terrestial insects & 0.00 & 0.00 & 0.00 & 2.60 & 6.25 & 0.01 \\
\hline Gammarus sp. & 0.00 & 0.00 & 0.00 & 1.30 & 3.13 & 0.00 \\
\hline Dikerogammarus villosus & 10.34 & 4.65 & 0.02 & 19.48 & 28.13 & 0.10 \\
\hline Palemon. sp. & 3.45 & 2.33 & 0.01 & 14.29 & 21.88 & 0.07 \\
\hline Procambarus clarkii & 0.00 & 0.00 & 0.00 & 3.90 & 6.25 & 0.01 \\
\hline Fish larvae (unidentified) & 3.45 & 2.33 & 0.01 & 3.90 & 9.38 & 0.01 \\
\hline Lepomis gibbosus & 0.00 & 0.00 & 0.00 & 1.30 & 3.13 & 0.00 \\
\hline Cyprinids (small: $<5 \mathrm{~cm}$ ) & 24.14 & 16.28 & 0.10 & 2.60 & 6.25 & 0.01 \\
\hline Cyprinids (large: $>5 \mathrm{~cm}$ ) & 0.00 & 0.00 & 0.00 & 3.90 & 6.25 & 0.01 \\
\hline Ictalurus punctatus & 13.79 & 6.98 & 0.04 & 0.00 & 0.00 & 0.00 \\
\hline Rodents & 3.45 & 2.33 & 0.01 & 1.30 & 3.13 & 0.00 \\
\hline
\end{tabular}

or interaction (df:1; $\mathrm{R}^{2}$ : 0.04987; F: 1.4424; p: 0.1774).

The CAP1 and CAP2 axes (squared canonical correlation of $\delta_{1}^{2}=0.782$ and $\delta_{2}^{2}=0.283$, respectively) separated the groups of specimens identified by the factor of season (Figure 1). The correlation of the variable size scored on the two CAP axes (CAP1 $\delta_{1}^{2}$ : 0.139; CAP1 $\delta_{1}^{2}:-0.990 ; \mathrm{r}^{2}: 0.3443$; p: 0.001) revealed that size characterized prey occurrence.

\section{Discussion}

The majority of studies investigating the diet of the European catfish have focused on its native area in Eastern Europe (see Carol et al. 2009 and references therein). Relatively fewer studies have investigated its diet in its introduced range in Italy (Rossi et al. 1991, Haubrock et al. 2019), which limits understanding the impact of this species. Despite a scarcity of information, the two ecosystems investigated in these studies are notably distinct, and the Arno River (Haubrock et al. 2019) is particularly noteworthy since its ichthyofauna community composition is entirely comprised of non-native species. While similar studies have been conducted on other piscivorous fish (see, e.g., Lorenzoni et al. 2002), this is the first report of seasonal shifts in the European catfish diet in Italy.

Rossi et al. (1991), for instance, noted that at a size of $\sim 30 \mathrm{~cm}$ the European catfish shifts from a crustacean-based diet to piscivory. Although their study was limited to one season, Haubrock et al. (2019) observed that immature individuals of a comparable size expressed no obvious prey preference, but rather consumed a diverse diet consisting of small cyprinids (and other small fishes), small crustaceans, and plants. During the present investigation 


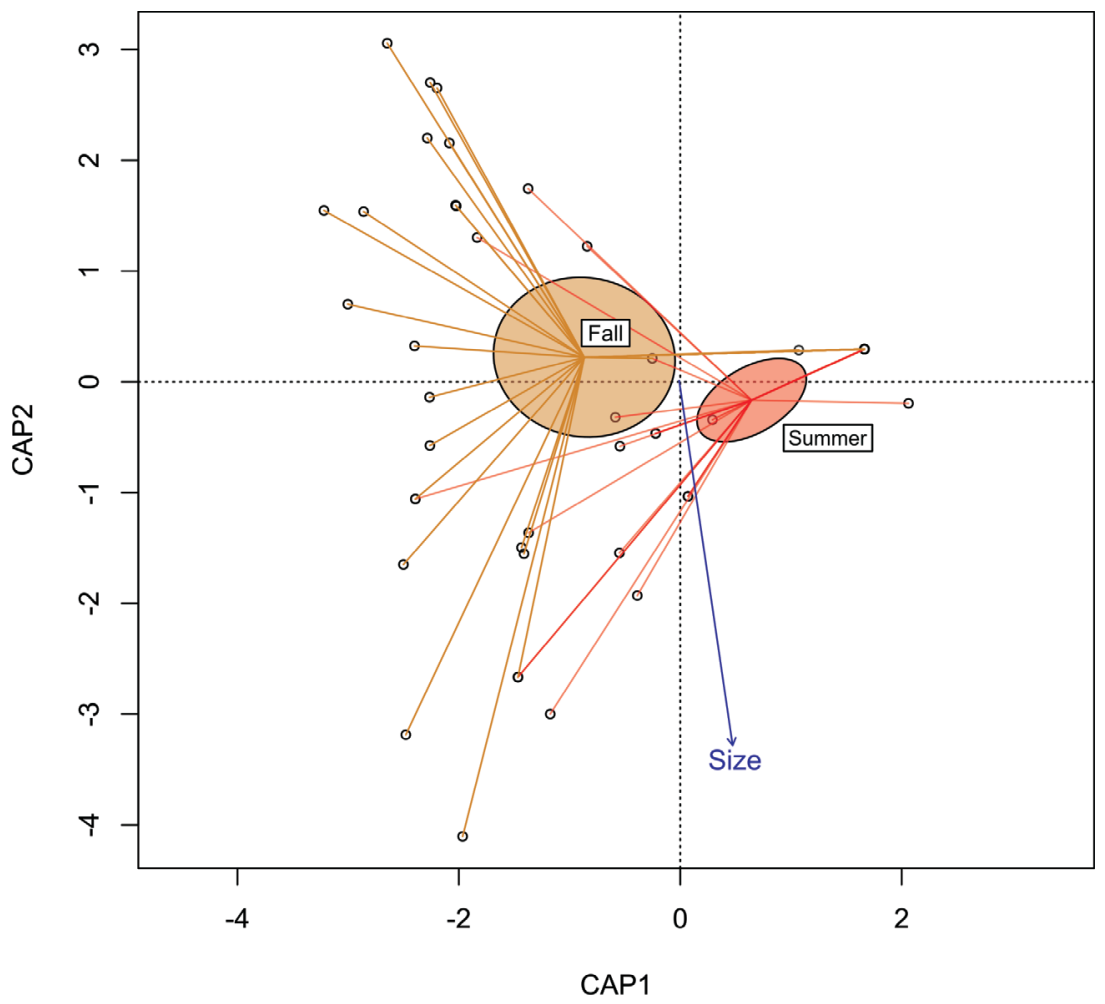

Figure 1. Two-dimensional scatter plot of the first and second principal coordinate axes (after resemblance matrix with Bray-Curtis distance matrix of dietary data, $\mathrm{n}$ samples $=73$ ) for the factor of season (summer, fall). Vectors of linear correlations between sizes are superimposed on the graph.

of the diet of $S$. glanis juveniles in fall, a similarly diverse pattern was noted, while a considerable percentage of stomachs contained algae and detritus, individuals predominantly fed on insects, followed by crustaceans, and to a lesser degree on fishes. The diversity of prey occurring in the $S$. glanis diet could have been the result of a heavily disturbed environment. However, while the occurrence of algae and detritus could have originated from accidental ingestion, it is noteworthy as it could be a dietary component, especially of immature individuals (Copp et al. 2009). Haubrock et al. (2019) argued that the strong resource overlap with the co-occurring invasive species I. punctatus could be the reason the less competitive $S$. glanis juveniles shifted to other potential food sources. However, invasive, and potentially predatory species like Dikerogammarus villosus, Palaemon sp., or P. parva (the latter combined with A. alburnus as cyprinids) are highly abundant in the section of the Arno studied (Haubrock et al. 2021a). Accordingly, we found that cyprinids comprised a considerable portion of the $S$. glanis diet. Another potential explanation could be that behavioral differences, i.e., the higher density of I. punctatus and their greater prey detection sensitivity, and not availability, were limiting factors.

Further, significant seasonal differences in the occurrence of prey species in the diet of $S$. glanis were identified. The reasons for this could be (i) seasonally varying occurrences of prey (Salfina and Burger 1985), (ii) dietary shifts in accordance with physiological requirements (Uys 1989), or (iii) shifts in competition with other co-occurring species. Similarly, interactions and especially niche overlap between the almost analogous cyprinid species $P$. parva and A. alburnus in the Arno River (Balzani et al. 2020) were not limiting despite the significant overlap, and this led to competition. While these potential reasons should be the aim of future studies, the variability in this predatory feeding behavior despite being limited to immature individuals is important. Although PERMANOVA $(\mathrm{p}=0.06)$ analysis did not 
identify this as significantly differentiating prey occurrences, CAP results suggested there was a significant relation. Here, the inclusion of larger sized, mature individuals should clarify whether similar trends observed by Haubrock et al. (2019) or Rossi et al. (1991) are pervasive across a wider fish size range.

Another relevant observation was the high number of empty stomachs. While it is difficult to determine the reason for this, it was previously argued that major drivers could be either competition with I. punctatus or increasingly unsuitable environmental conditions (Haubrock et al. 2020). While the Arno River is not the ideal environment to investigate this predator's impact on nearly absent native species (Haubrock et al. 2021a), the present study indicated this species has a generalist diet that could impact multiple resource types. Based on the prey occurrences observed, it can also be argued that the diet of $S$. glanis, and therefore its feeding impact on the community of potential prey, can affect species beyond those previously identified as prey species such as cyprinids and crustaceans. This pertains especially to aquatic insects, but also to various other fishes (e.g., Lepomis gibbosus (L.)) and small rodents (Rattus norvegicus) that were observed in its diet.

Considering the findings of this study, it can be argued that the reasons for the recent decline in $S$. glanis in the Arno River depends on several factors including (i) increasing competition with other non-native predators, (ii) a decline in native prey species, and (iii) progressive environmental degradation. However, while this study presents novel dietary information in two seasons of a damaging invasive species, it raises further issues that ought to be addressed in the future: (a) information on mature individuals is scarce and it could differ from data on juveniles in the Arno River; (b) the reasons for the ontogenic diet shift remain unclear; (c) the reasons for the decline in S. glanis require further elucidation. These issues are all of ecological and economic interest since local anglers have not yet shifted to targeting $I$. punctatus as a valuable game species.
Acknowledgments. I would like to thank Paride Balzani for his helpful comments on a previous version of this manuscript and for assistance with sampling. Further, I would like to thank Ross N. Cuthbert for his proofreading and critical thinking.

\section{ORCID ID}

Phillip J. Haubrock (iD https://orcid.org/0000-0003-2154-4341

\section{References}

Alexander, M.E., Dick, J.T., Weyl, O.L., Robinson, T.B., Richardson, D.M. (2014). Existing and emerging high impact invasive species are characterized by higher functional responses than natives. Biology Letters, 10(2), 20130946.

Balma, G.A., Delmastro, G.B., Forneris, G. (1989). Segnalazione di alcune specie ittiche esotiche d'importazione in Italia settentrionale, con particolare riferimento alle acque piemontesi (Pisces: Osteichthyes). Atti Della Societŕ Italiana Di Scienze Naturali E Del Museo Storia Naturale Milano, 130(7), 109-116.

Balzani, P., Gozlan, R.E., Haubrock, P.J. (2020). Overlapping niches between two co-occurring invasive fish: the topmouth gudgeon Pseudorasbora parva and the common bleak Alburnus alburnus. Journal of Fish Biology, 97(5), 1385-1392.

Batistic, M., Tutman, P., Bojanic, D., Skaramuca, B., Ko, V., Bartulovic, V. (2005). Diet and diel feeding activity of juvenile pompano (Trachinotus ovatus)(Teleostei: Carangidae) from the southern Adriatic, Croatia. Marine Biological Association of the United Kingdom. Journal of the Marine Biological Association of the United Kingdom, 85(6), 1533-1534.

Bellard, C., Cassey, P., Blackburn, T.M. (2016). Alien species as a driver of recent extinctions. Biology Letters, 12(2), 20150623.

Boulętreau, S., Verdeyroux, P., Lorthiois, E., Azémar, F., Compin, A., Santoul, F. (2016). Do you eat or not? Predation behaviour of European catfish (Silurus glanis) toward live bait on a hook. The Open Fish Science Journal, 9(1). 8-14.

Carol, J., Benejam, L., Benito, J., García-Berthou, E. (2009). Growth and diet of European catfish (Silurus glanis) in early and late invasion stages. Fundamental and Applied Limnology, 174(4), 317-328.

Castaldelli, G., Pluchinotta, A., Milardi, M., Lanzoni, M., Giari, L., Rossi, R., Fano, E.A. (2013). Introduction of exotic fish species and decline of native species in the lower Po basin, north-eastern Italy. Aquatic 
Conservation: Marine and Freshwater Ecosystems, 23(3), 405-417.

Copp, G.H., Robert Britton, J., Cucherousset, J., García-Berthou, E., Kirk, R., Peeler, E., Stakènas, S. (2009). Voracious invader or benign feline? A review of the environmental biology of European catfish Silurus glanis in its native and introduced ranges. Fish and Fisheries, 10(3), 252-282.

Crystal-Ornelas, R., Lockwood, J.L. (2020). The 'known unknowns' of invasive species impact measurement. Biological Invasions, 22(4), 1513-1525.

Cucherousset, J., Horky, P., Slavík, O., Ovidio, M., Arlinghaus, R., Boulętreau, S., ... Santoul, F. (2018). Ecology, behaviour and management of the European catfish. Reviews in Fish Biology and Fisheries, 28(1), 177-190.

Cunico, A.M., Vitule, J.R.S. (2014). First records of the European catfish, Silurus glanis Linnaeus, 1758 in the Americas (Brazil). BioInvasions Records, 3(2), 117-122.

Cuthbert, R. N., Pattison, Z., Taylor, N. G., Verbrugge, L., Diagne, C., Ahmed, D. A., ... Courchamp, F. (2021). Global economic costs of aquatic invasive alien species. Science of the Total Environment, 145238.

Gallardo, B., Clavero, M., Sánchez, M.I., Vilà, M. (2016). Global ecological impacts of invasive species in aquatic ecosystems. Global Change Biology, 22(1), 151-163.

Gherardi, F., Bertolino, S., Bodon, M., Casellato, S., Cianfanelli, S., Ferraguti, M., ... Tricarico, E. (2008). Animal xenodiversity in Italian inland waters: distribution, modes of arrival, and pathways. Biological Invasions, 10(4), 435-454.

Gualtieri, M., Mecatti, M. 2005. Indagine sulla diffusione del siluro (Silurus glanis) nell'Arno fiorentino. Prima relazione 2005. Technical report. pp 11.

Haubrock, P.J., Balzani, P., Azzini, M., Inghilesi, A.F., Veselý, L., Guo, W., Tricarico, E. (2019). Shared histories of co-evolution may affect trophic interactions in a freshwater community dominated by alien species. Frontiers in Ecology and Evolution, 7, 355.

Haubrock, P.J., Azzini, M., Balzani, P., Inghilesi, A.F., \& Tricarico, E. (2020). When alien catfish meet-Resource overlap between the North American Ictalurus punctatus and immature European Silurus glanis in the Arno River (Italy). Ecology of Freshwater Fish, 29(1), 4-17.

Haubrock, P.J., Pilotto, F., Innocenti, G., Cianfanelli, S., Haase, P. (2021a). Two centuries for an almost complete community turnover from native to non-native species in a riverine ecosystem. Global Change Biology, 27(3), 606-623.

Haubrock, P. J., Bernery, C., Cuthbert, R. N., Liu, C., Kourantidou, M., Leroy, B., ... Gozlan, R. E. (2021b). What is the recorded economic cost of alien invasive fishes worldwide? Research Square, http://doi.org/10.21203/rs.3.rs-381243/v1
Hickley, P., North, R., Muchiri, S.M., Harper, D.M. (1994). The diet of largemouth bass, Micropterus salmoides, in Lake Naivasha, Kenya. Journal of Fish Biology, 44(4), 607-619.

Hulme, P.E., Pyšek, P., Nentwig, W., \& Vilŕ, M. (2009). Will threat of biological invasions unite the European Union. Science, 324(5923): 40-41.

Krebs, C.J. (1998). Ecological methodology. Second edition. University of of British Columbia. Vancouver: 1-620.

Levins, R. (1968). Evolution in changing environments: some theoretical explorations. Princeton University Press.

Lorenzoni, M., Corboli, M., Dörr, A.J.M., Giovinazzo, G., Selvi, S., Mearelli, M. (2002). Diets of Micropterus salmoides Lac. and Esox lucius L. in Lake Trasimeno (Umbria, Italy) and their diet overlap. Bulletin Francais de la Peche et de la Pisciculture, 365/366, 537-547.

Malcolm, J.R., Markham, A. (2000). Global warming and terrestrial biodiversity decline. Washington, DC: WWF.

Nocita, A. (2002). Carta Ittica della Provincia di Firenze. Assessorato Agricoltura Caccia e Pesca. e Museo di StoriaNaturale, pp. 254.

Nocita, A., Zerunian, S. (2007). L'ittiofauna aliena nei fiumi e nei laghi d'Italia. Biologia Ambientale, 21(2), 93-96.

Nocita, A., Tricarico, E., Bertolino, S. (2017). Fine - scale analysis of heavily invaded Italian freshwater fish assemblages. Integrative Zoology, 12(6), 500-511.

Nunes, A.L., Tricarico, E., Panov, V.E., Cardoso, A.C., Katsanevakis, S. (2015). Pathways and gateways of freshwater invasions in Europe. Aquatic Invasions, 10(4), 359-370.

Oksanen, J., Kindt, R., Legendre, P., O’Hara, B., Stevens, M. H.H., Oksanen, M.J., Suggests, M.A.S.S. (2007). The vegan package. Community Ecology Package, 10(631-637), 719.

Pianka, E.R. (1974). Niche overlap and diffuse competition. Proceedings of the National Academy of Sciences, 71(5), 2141-2145.

Poulin, R., Paterson, R.A., Townsend, C.R., Tompkins, D.M., \& Kelly, D.W. (2011). Biological invasions and the dynamics of endemic diseases in freshwater ecosystems. Freshwater Biology, 56(4), 676-688.

Rees, E.A., Edmonds-Brown, V.R., Alam, M.F., Wright, R.M., Britton, J.R., Davies, G.D., Cowx, I.G. (2017). Socio-economic drivers of specialist anglers targeting the non-native European catfish (Silurus glanis) in the UK. PloS one, 12(6), e0178805.

Rossi, R., Trisolini, R., Rizzo, M.G., Dezfuli, B.S., Franzoi, P., Grandi, G. (1991). Biologia ed ecologia di una speciealloctona, il siluro (Silurus glanis L.)(Osteichthyes, Siluridae), nella parte terminale del fiume Po. Atti della Societa Italiana di Scienze Naturali e del Museo Civico diStoria Naturale di Milano 132, 69-87. 
Safina, C., Burger, J. (1985). Common tern foraging: seasonal trends in prey fish densities and competition with bluefish. Ecology, 66(5), 1457-1463.

Schoener. T.W. (1986). Mechanistic approaches to community ecology: a new reductionism. American Zoologist, 26, 81-106.

Seebens, H., Blackburn, T.M., Dyer, E.E., Genovesi, P., Hulme, P.E., Jeschke, J. M., ... Essl, F. (2017). No saturation in the accumulation of alien species worldwide. Nature Communications, 8(1), 1-9.

Stellati, L., Borgianni, N., Bissattini, A.M., Buono, V., Haubrock, P.J., Balzani, P., ... Vignoli, L. (2019). Living with aliens: suboptimal ecological condition in semiaquatic snakes inhabiting a hot spot of allodiversity. Acta Oecologica, 100, 103466.
Uys, W. (1989). Aspects of the nutritional physiology and dietary requirements of juvenile and adult sharptooth catfish, Clarias gariepinus (Pisces: Clariidae). PhD Thesis, Rhodes University, South Africa.

Wallace Jr, R.K. (1981). An assessment of diet-overlap indexes. Transactions of the American Fisheries Society, 110(1), 72-76.

Whittaker, R.H. (1973). Ordination and classification of communities. W. Junk, The Hague, NL.

Zimmerman, D.W. (1987). Comparative power of Student $t$ test and Mann-Whitney $U$ test for unequal sample sizes and variances. The Journal of Experimental Education 55, 171-174. 